\title{
Geleceği İnşa Etmek: Konut Binalarında Gün Işığı ve COVID-19 Üzerine Bir Değerlendirme
}

\author{
Gülten ŞENTÜRK SIPAHi ${ }^{1 *(D)}$, Ruşen YAMAÇLI ${ }^{2}$ (D) \\ ORCID 1: 0000-0001-6853-9502 \\ ORCID 2: 0000-0001-9659-9246 \\ ${ }^{1}$ Kırşehir Ahi Evran Üniversitesi, Mühendislik-Mimarlık Fakültesi, Mimarlık Bölümü, 40100, Kırşehir, Türkiye. \\ ${ }^{2}$ Eskişehir Teknik Üniversitesi, Mimarlık ve Tasarım Fakültesi, Mimarlık Bölümü, 26000, Eskişehir, Türkiye. \\ *e-mail: gltnsenturk@gmail.com \\ Öz \\ COVID-19 salgınından önce de insanlar zamanının \%90'ını kapalı ortamlarda geçiriyordu. Şimdi ise çalışırken ve \\ eğitimlerine devam ederken her zamankinden daha fazla evlerinde vakit geçiriyorlar. Bu durum konut binalarının \\ tasarımı ve planlaması üzerinde yeniden düşünülmesini gerektiriyor. Sadece salgın zamanları olmasa da COVID- \\ 19 ve karantina süreci, yapılı ortamın tümünde bir sorun teşkil etmesine rağmen özellikle konut yapıları olmak \\ üzere kapalı mekânlarda insan sağlığının korunmasının gerekliliği ile ilgili bir uyarıcı olmaktadır. Pandemi süreci \\ sona erse bile mimarlık anlayışının eskisi gibi olmayacağı kesindir. Bu makalede, konut yapılarında insan sağlığı \\ ve COVID-19 etkileri araştırılmıştır ve gelecekteki konut anlayışı için potansiyel bir çözüm olarak iç ortam \\ kalitesinin önemli bir bileşeni olan gün ışığı aydınlatmasının önemi ortaya konmuştur.
}

Anahtar Kelimeler: Konut binaları, COVID-19 pandemisi, sağlık, refah, gün ışığı

\section{Building the Future: An Evalution on Daylight and COVID-19 in Residental Buildings}

\begin{abstract}
Even before the COVID-19 epidemic, people spent $90 \%$ of their time indoor. For now, they are spending more time at their home than ever before while working and continuing their education. This situation requires a reconsider of the design and planning of residential buildings. Although there are not only epidemic times, COVID-19 and the quarantine process pose a problem in the entire built environment, it is a warning about the necessity of protecting human health indoors, especially residential buildings. Even if the pandemic process ends, it is certain that the understanding of architecture will not be the same as before. In this article, human health and the effects of COVID-19 in residential buildings were investigated and the importance of daylight lighting, which is an important component of indoor environment quality, as a potential solution for future housing concept has been revealed.
\end{abstract}

Keywords: Residential buildings, COVID-19 pandemic, health, well-being, daylight

Atıf/Citation: Şentürk Sipahi, G, Yamaçlı, R. (2021). Geleceği İnşa Etmek: Konut Binalarında Gün Işığı ve COVID19 Üzerine Bir Değerlendirme. Journal of Architectural Sciences and Applications, 6 (1), 374-383. DOI: $10.30785 /$ mbud. 874426 


\section{Giriş}

Endüstri öncesinde insanlar zamanının önemli bir kısmını başlıca tarım, yapı ve zanaat temelli işlerle gün ışığına maruz kalarak dışarıda geçirirlerdi. 19. ve 20. yüzyıllarda, sanayileşmiş işgücü piyasaları nedeniyle kentsel yoğunlaşmadaki artış ve elektrikli aydınlatma, inşaat teknikleri ve iç mekân iklim kontrol teknolojilerindeki ilerlemeler iç mekân kullanım süresinin giderek uzamasına neden oldu (Amundadottir, Rockcastle, Khanie ve Andersen, 2017). Sanayileşmiş modern dünyamızda ise insanlar zamanının çoğunu (\%90) iç mekânlarda geçiriyor (Klepeis, Nelson, Ott, Robinson, Tsang, Switzer, ... Engelmann, 2001). 11 Mart 2020'de Dünya Sağlık Örgütü'nün SARS-CoV-2'nin neden olduğu COVID-19 hastalığını bir pandemi olarak nitelendirmesiyle (WHO, 2020) birçok insanın yaşamlarını sürdürürken uzun bir süre boyunca aynı yapılı ortamda (evde) kalması gerekliliği bu süreyi uzattı. Dahası eğitimlerine ve çalışmalarına evden devam eden insanlar yaşam tarzlarındaki değişikliklere hızla adapte olmak zorunda kaldı (Saadat, Rawtani ve Hussain, 2020). Tüm bunların sonucunda konut bir yaşam alanından daha fazlası haline geldi.

Konut binaları, sosyal refahı belirlemeleri sebebiyle nüfus sağlığı için çok önemlidir. Buna ek olarak, kısa bir sürede hızla ve kolayca yayılan COVID-19'un viral yayılma riskini önlemek amacıyla evde kalınması gereken karantina döneminde konutlar kritik öneme sahipti (Tokazhanov, Tleuken, Guney, Turkyilmaz ve Karaca, 2020). Kişiden kişiye büyük ölçüde farklılık gösteren bu deneyim insanların fiziksel ve ruhsal sağlığı üzerinde olumsuz etkilere sebep olmuş (Daniela, Gola, Letizia, Marco, Fara, Rebecchi, ... Capolongo, 2020) ve kişisel çevresindeki eksiklikleri daha fark edilebilir bir duruma getirerek konut tasarımına dikkat çekmiştir. Evde kalınması gereken süreç sona erse de beklentiler karantina döneminden sonra bile daha fazla insanın evlerinden çalışacağı yönündedir. Bu nedenle ev tasarımı geleceğinin değişeceği olasıdır (Megahed ve Ghoneim, 2020). Sonuç olarak, COVID-19 pandemisinin sonuçları ve bunun tekrarlanmasının olası riski, konut planlamasına iç mekân açısından yeni bir sağılı konseptinin uygulanmasının gerekliliğini vurgulamaktadır.

\section{Materyal ve Yöntem}

Bu makale, Aralık 2019 tarihinde ortaya çıkan ve dünyada hızla yayılan COVID-19 hastalığı kapsamında alınan tedbirlerle öne çıkan konut yapı tasarımlarının insan sağlığı ile ilişkisinin önemini açıklayan metinleri ve gelecekteki konut yapılarına ilişkin tasarım önerilerini içermektedir. Çalışmada, konu dahilinde çalışmanın amacına yönelik literatür tarama çalışması yapılmış, ilgili kurum ve kuruluşların raporlarından ve güncel bilimsel verilerden yararlanılmıştır.

Araştırma genelinde yapılı çevre ve iç mekân tasarımlarının insan üzerindeki etkileri incelenmiş ve son zamanlarda gündemimizde olan COVID-19 hastalığı bağlamında gün ışığı ve konut tasarımı yeniden ele alınmıştır. Sonuç olarak ise insan sağlığını destekleyen ve iyileştiren tasarım stratejilerinin benimsenerek mimari gelişim sürecine katkı sağlaması hedeflenmektedir.

\section{Araştırma Bulguları}

Mimari tasarımda gün ışığı aydınlatmasının çevre, ekonomi ve insan sağlığı üzerinde birçok olumlu sonucu vardır. Bu bağlamda COVID-19 salgınıyla birlikte önemini bir kez daha yineleyen yapılı çevre ve insan sağlığı arasındaki ilişki tekrar gözden geçirilmelidir. Çalışmanın bu bölümünde salgın sırasında ve sonrasında ortaya çıkabilecek etkilerine karşı gün ışığının dahil olduğu özellikle konut binalarını kapsayan mimari çözümler için araştırma bulguları sunulmuştur.

\subsection{Yapılı Çevre ve İnsan Sağlığı Arasındaki ílişki}

Mimarlık ve sağlık arasındaki ilişki, bina tasarım kriterleri arasında tarihte çok az ilgi görmüş olsa da son yıllarda hem açık hem de kapalı alanlardaki insan sağlığı ve kentsel yapılı çevre arasındaki ilişki üzerine yapılan araştırmalar artmıştır (Thompson, 2013; Hoisington, Stearns-Yoder, Schuldt, Beemer, Maestre, Kinney ve Brenner, 2019). Dünya Sağlık Örgütü sağlığı "yalnızca hastalık ve rahatsızlığın olmayışı değil, bir bütün olarak fiziksel, zihinsel ve sosyal iyi olma hali" olarak tanımlar (WHO, 1948). Fiziksel iyi olma durumu vücudun uygun çalışması ve hastalığa karşı dirençliliği olarak tanımlanır. Zihinsel iyi oluş sadece akıl hastalığı olmaması değil zihinsel dayanıklılık, memnuniyet, güven ve huzurdan oluşur. Sosyal refah ise bireyin başkalarıyla anlamlı pozitif ilişkiler kurma ve sürdürme becerisidir; bireyin aidiyet duygusu ve sosyal katılım tarafından belirlenir (Awada, Becerik-Gerber, Hoque, O'Neill, Pedrielli, Wen ve Wu, 
2020). Yapılı çevre ve sağlık arasındaki ilişkiyi keşfetmek için yapılı çevrenin fiziksel özellikleri, sağladığı olanaklar ve kişinin bireysel özellikleri değerlendirilmesi gereken önemli faktörlerdir. Nüfus, ulaşım altyapısı, arazi kullanımı, yeşil alana erişim, kentsel iklim, sağlıklı kaynaklara erişim, fazla yoğunluk sebebiyle yaygın olan kirletici maddelere maruz kalma (Frank, Iroz-Elardo, MacLeod ve Hong, 2019) gibi büyük ölçekli planlamadan mekân organizasyonu, iç hava kalitesi, aydınlatma, akustik ve termal koşullar gibi küçük ölçekli planlamaya kadar birçok yapı özellikleri açısından mekânlar farklıık gösterir. Bunların her biri fiziksel ve zihinsel sağlığı etkileyebilir (Şekil 1).

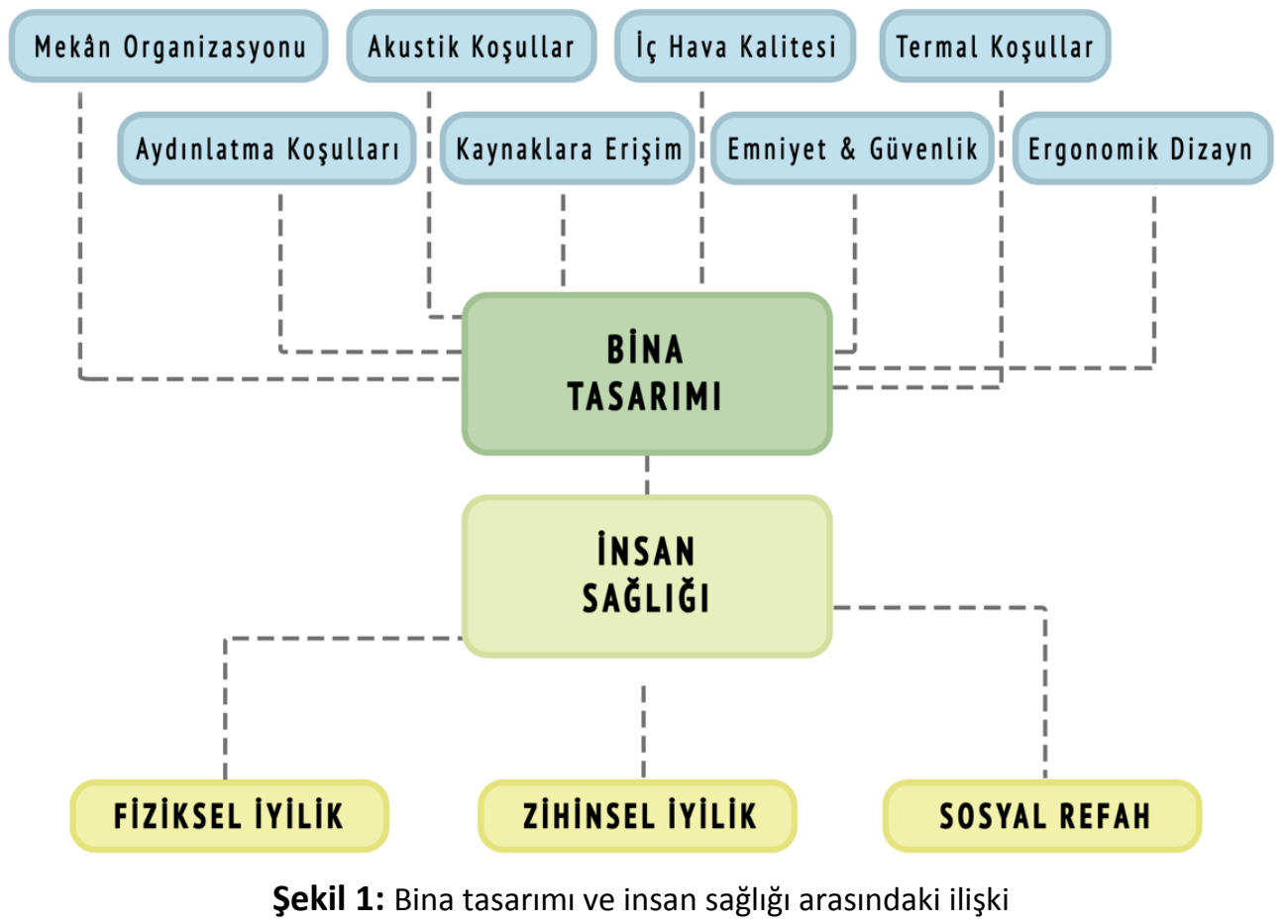

Son zamanlarda bina tasarımlarında düşük enerji tüketimini ve binaların çevre üzerindeki etkilerini azaltmayı vurgulayan bir eğilim vardır (Baleta, Mikulčić, Klemeš, Urbaniec ve Duić, 2019; Ingrao, Messineo, Beltramo, Yigitcanlar ve loppolo, 2018). Ancak bina tasarım kriterleri, diğer etkenlere ek olarak bina sakinlerinin sağlığı ve refahını desteklemelidir (Amerio, Brambilla, Morganti, Aguglia, Bianchi, Santi, ... Capolongo, 2020). Dünya Sağlık Örgütüne göre "iç ortam yalnızca yaşam süremiz boyunca iç mekânda geçirilen zaman (yaklaşık \%90) nedeniyle değil, aynı zamanda her gün karşılaşılan sağlık ve güvenlik tehditlerinin birleşimi nedeniyle insan sağlığı ve refahı için kilit önemdedir" (WHO, 2013). İç mekân kalitesi; termal konfor, iç hava kalitesi, görsel konfor ve akustik konfor olarak değerlendirilirken bunların yanı sıra binaların mekânsal düzeni, binanın konumu ve doğa ile olan bağlantısı ile alakalıdır (Mujan, Anđelković, Munćan, Kljajić ve Ružić, 2019). Bu nedenle iç mekân kalitesini oluşturan faktörlerin bina tasarımlarındaki yeterlilik düzeyleri insan sağlığı için önemlidir.

\subsection{Konutlarda Gün Işığının İnsan Sağlığı ve COVID-19 Üzerindeki Etkileri}

Gün ışığı, gün boyunca güneş tarafından sağlanan ve Dünya üzerindeki birçok canlının gelişmesi, üremesi ve hayatta kalması için büyük önem taşıyan bir etkendir. Mimarlık ise insanın barınma ihtiyacı ile başlayan ve günümüzde fiziksel çevreyi oluşturan yapılaşmaların neredeyse tümünde gördüğümüz, yaşamın bir parçasıdır. Mimari tasarımda gün ışığı, mekân tanımlamasının ana unsurlarından biri olarak kabul edilir ve dolayısıyla mekân kalitesinin önemli bir bileşenidir (Hafiz, 2015). Mimarlık tarihinin başından bu yana tasarıma gün ışığını dâhil etmek önemini asla kaybetmemiş hatta sunduğu avantajlar bakımından daha önemli bir hale gelmiştir.

COVID-19 müdahalesi için gerekli olan evde kalma tutumuyla, konut özellikleri insanların yaşamlarında daha fazla önem kazanmıştır. Bir araştırmanın anket sonuçları, COVID-19 pandemisi sebebiyle uygulanan zorunlu karantina döneminin sağlıksız bir yaşam tarzı ile birlikte zihinsel sağlık için bir engel olduğunu ortaya koymuştur. Özellikle sosyal ve fiziksel hareketsizliğin, sağlıksız beslenmenin ve kötü uyku kalitesinin zihinsel ve duygusal sağlık üzerinde olumsuz etkileri olduğu sonucuna varılmıştır (Ammar, Trabelsi, Brach, Chtourou, Boukhris, Masmoudi, ... Hoekelmann, 2020). Yakın zamanda 
yapılan diğer çalışmalar tarafından da onaylandığı üzere, karantinaya alınan bireylerin karantina dışındakilere kıyasla daha fazla korku, sinir, öfke, duygusal yorgunluk ve uyku problemleri ile birlikte psikolojik sıkıntı, anksiyete ve depresif semptomlar gösterdiği bulunmuştur (Odriozola-González, Planchuelo-Gómez, Irurtia ve De Luis-García, 2020; Moccia, Janiri, Pepe, Dattoli, Molinaro, De Martin, ... Di Nicola, 2020; Pfefferbaum ve North, 2020; Wang, Pan, Wan, Tan, Xu, Ho ve Ho, 2020). Bunlara ek, yapılan diğer araştırmalarda COVID-19 ölümlerinin bir sebebi olarak D vitamini eksikliğinden bahsedilmiştir (Ilie, Stefanescu ve Smith, 2020; Rhodes, Subramanian, Laird, Griffin ve Kenny, 2021).

Yapılı ortamlarda gün ışı̆̆ı kullanımının birçok açıdan olumlu etkileri vardır (Şekil 2). Gün ışığı, günün saatine ve mevsimlere göre değişen yoğunluğu nedeniyle yapay aydınlatmaya göre daha iyi bir görsel ortam oluşturur. Dinamik bir iç ortam sağlayarak ve kullanıcıların görsel konfor, estetik ve mekân algısı konusundaki deneyimini iyileştirerek, bina sakinlerinin sağlığını ve refahını artırmada önemli bir rol oynar (Abidi ve Rajagopalan, 2020; Ullah, 2014). Ayrıca kaynakların korunmasında ve enerji verimliliğinde büyük öneme sahiptir. Sonuçta, gün ışığının davranışsal, ekonomik ve çevresel sonuçları ile birlikte görsel performans, iyi görüş, D vitamini üretimi, sirkadiyen ritim ve psikoloji gibi insan sağlığı üzerinde doğrudan ve dolaylı yoldan pek çok özel faydası vardır (Knoop, Stefani, Bueno, Matusiak, Hobday, Wirz-Justice, ... Norton, 2020; Morin, Carrier, Bastien ve Godbout, 2020; Edwards ve Torcellini, 2002). Bunlara bakılarak kapalı kaldığımız karantina sürecinin olumsuz etkilerine karşı insan sağlığı risklerini azaltma konusunda gün ışığı, bina tasarımlarında potansiyel bir önlem olarak kabul edilebilir (Şekil 3).

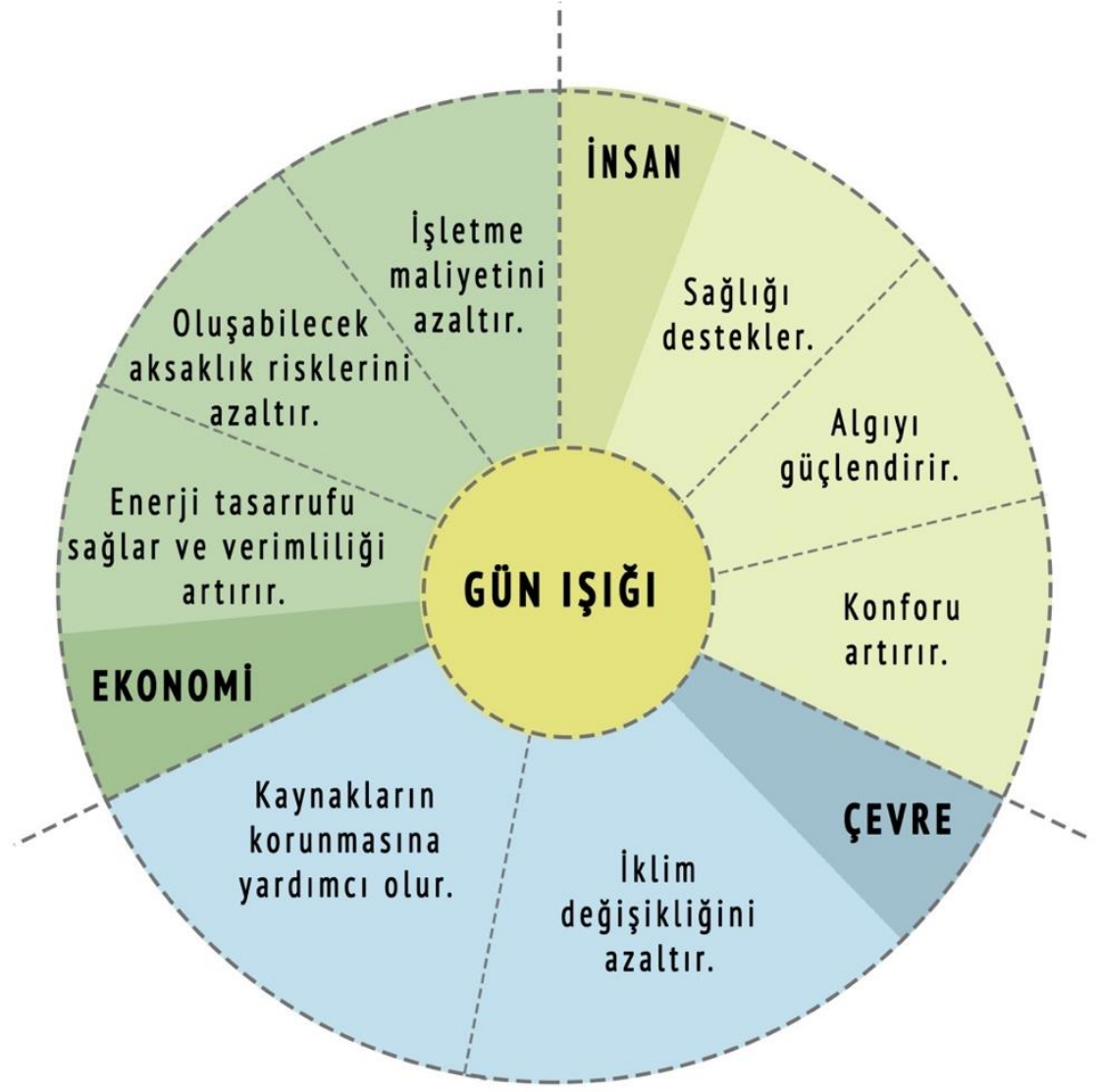

Şekil 2: Yapılı çevrede gün ışığı kullanımının etkileri 


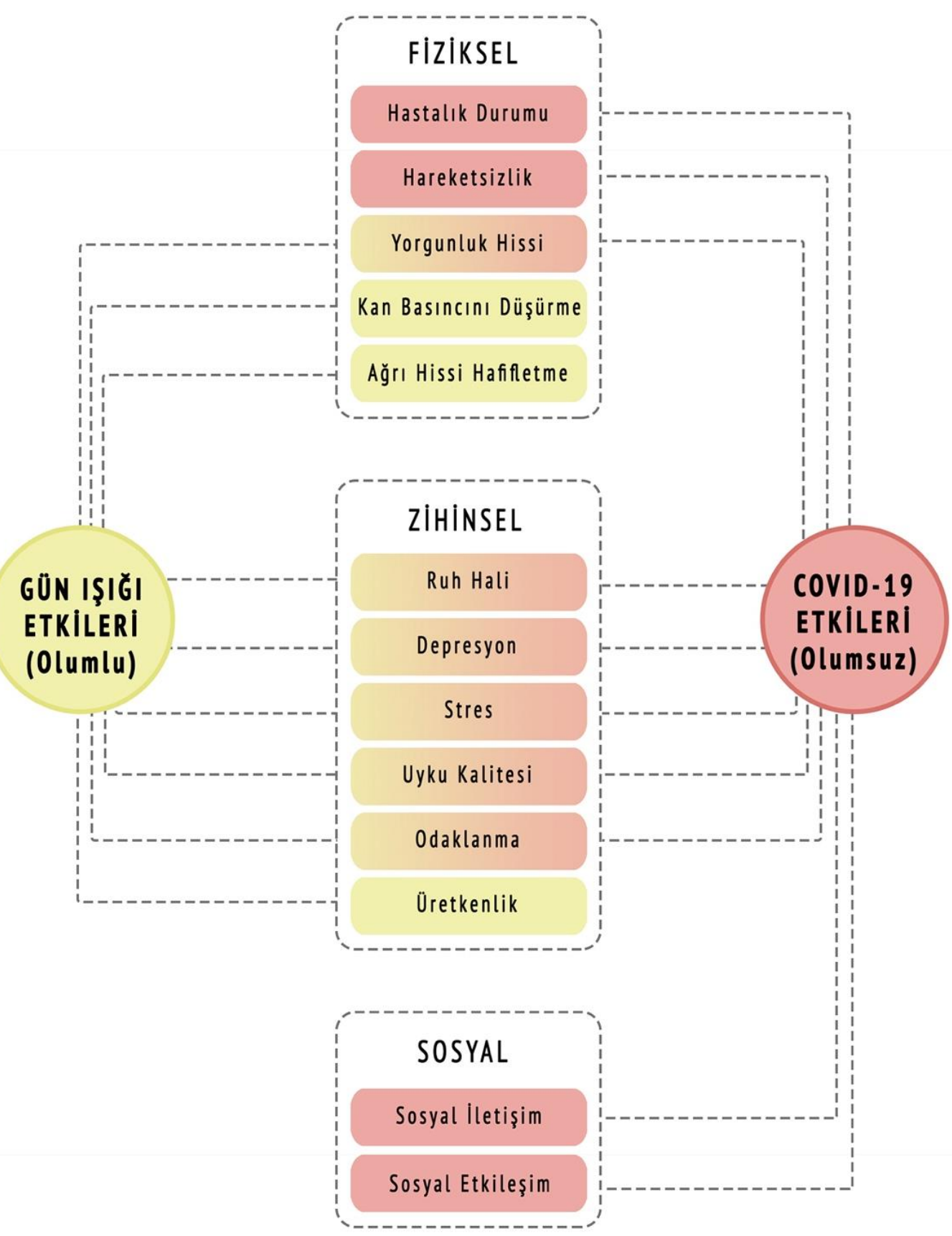

Şekil 3: Gün ışı̆̆ı ve COVID-19 salgınının insan sağlığı üzerindeki etkileri

Güneş ışığı, insan sağlığı üzerindeki etkilerinin yanında potansiyel bakteri öldürücü etkileri nedeniyle binalarda patojenlerin yayılmasına karşı bir tampon olarak kabul edilmiştir ve bazı bulaşıcı virüslerin iç mekânlarda yaşayabilirliğini kontrol etmek için bir azaltma stratejisidir (Dietz, Horve, Coil, Fretz, Eisen ve Van Den Wymelenberg, 2020). Bu kapsamda binalarda bulunan güneş ışığının ve temiz havanın havadaki patojenlerin geçişini etkileyebileceğine dair kanıtlar bulunmaktadır. Bir araştırmaya göre, antibiyotiklerin keşfinden önce hem havanın hem de güneş ışığının enfeksiyona karşı önemli koruyucular olduğu kabul ediliyordu (Hobday ve Dancer, 2013). Bir başka araştırmada ise karanlık kontrol grubundaki virüs yarı ömrü 31,6 dakika iken simüle edilmiş güneş ışığında yaklaşık 2,4 dakika olarak ciddi ölçüde azalmış olduğu tespit edildi (Schuit, Gardner, Wood, Bower, Williams, Freeburger ve Dabisch, 2020).

COVID-19 pandemisine sebep olan SARS-CoV-2 üzerindeki etkileri henüz bilinmiyor olsa da yapılan çalışmalar sayesinde grip gibi bazı bulaşıcı virüslerin güneş ışığına duyarlı olduğu ve hayatta kalma süresinde etkili olduğu biliniyor. Gün ışığının SARS-CoV-2 üzerindeki etkilerini anlamak için daha fazla araştırmaya intiyaç vardır. Ancak güneş ışığı ve dışarıdaki temiz havanın bina tasarımları ile olan 
ilişkisinin güçlendirilmesi bulaşıcı virüslerin hayatta kalmasını ve yayılmasını engelleyebileceği, kullanıcılar için daha sağlıklı ortamlar sağlayabileceği açıktır.

\subsection{COVID-19 Pandemisinin Öğrettikleri}

Insanın yaşam biçimini şekillendiren pandemi gibi olağanüstü durumlar ve mimari birbiriyle yakından ilişkilidir. Bir salgın için ilaç geliştirmeden önce etkisini azaltmada fiziksel ve yapılı çevre tasarımı etkili bir çözümdür (Megahed ve Ghoneim, 2020). Öte yandan COVID-19 gibi salgın hastalıklar, kent planlaması ve konut iç mekânları dahil olmak üzere enfeksiyon korkusu nedeniyle çevreyi şekillendirmiş, son yüzyıllarda mimaride ve şehirleşmede çeşitli gelişmelere sebep olmuştur (Tokazhanov, Tleuken, Guney, Turkyilmaz ve Karaca, 2020). Yapılı çevre bir salgını kontrol altına alabilecek büyük bir etkiye sahipken bir pandemi de yapılı çevrenin gelişmesinde aynı etkiye sahiptir.

Enfekte vakaların çoğu fazla miktarda yapılaşma bulundurmaları ve kalabalık alanlara sahip olmaları sebebiyle şehirlerde meydana gelmiştir (Committee for the Coordination of Statistical Activities). Kamusal alanların yoğun olmasının yanı sıra çok katı konutların standart planlaması ve kompakt yapılandırılması vakaların artmasına sebep olmuştur. Ayrıca karantina döneminde, aşırı kalabalık apartmanlarda konut içi olanaklarının yetersiz olması özellikle çocuklar, yaşlılar ve risk grubundakiler için virüsün ev içi bulaşması bir sorun haline gelmiştir (Dietz, Horve, Coil, Fretz, Eisen ve Van Den Wymelenberg, 2020). Bu sebeple konut binalarının sürdürülebilirlik gereksinimleri, insanlığın uzun yıllar boyunca karşı karşıya kalacağı COVID-19 benzeri pandemilerle yeni gerçekliğe uyarlanmalıdır.

Bahsedilen bilgiler doğrultusunda konut tasarımlarında daha fazla doğal ışık, daha iyi havalandırma, daha az toksik madde, bitkileri ve doğal malzemeleri dahil etme gibi stratejilerle sağlığı iyileştirmeye yönelik bir yaklaşım gereklidir (Altena, Baglioni, Espie, Ellis, Gavriloff, Holzinger, ... Riemann, 2020). Bazı ısı yalıtımı gerekçeleri sebebiyle zor olsa da binalarda hava kalitesini artırmak ve gün ışığını elde etmek için daha büyük boyutta pencereler, çatı pencereleri, çatı terasları, balkonlar ve avluların konut tasarımları için standart hale gelmesi mümkündür (Pinheiro ve Luís, 2020). Ayrıca temiz havaya ve güneş ışığına yeterli seviyede maruz kalmak için dışarıdaki bir alana erişim bu noktada önemlidir.

\section{Sonuç ve Öneriler}

Günümüzde devam eden COVID-19 deneyimi son zamanlarda yapılan birçok alandaki çalışmalarla gündeme geldiği gibi mimarlık için de bir sorun olarak aynı ilgiyi görmüştür. Bu alanda özellikle konut binaları olmak üzere daha fazla dayanıklılık için yapılı çevrenin yeniden düşünülmesi ve iyileştirilmesi gibi birçok konu başlığı ele alınmıştır.

Iletişim kaynakları ve sosyal medya tarafından edinilen bilgilere göre alınan ani kararlar doğrultusunda uygulanan kısıtlamalar dünya genelinde birçok soruna yol açtı ve insanlar bu duruma ayak uydurmakta epey zorlandı. Salgın sona erdiğinde ise alınan önlemlerin birçoğu önemini kaybedecektir. Benzer bir olağanüstü durumla tekrar karşılaşma olasılığı olmasa bile insanın yaşam tarzı gereği yapılı çevrenin ve iç ortam kalitesinin insan üzerindeki etkilerini anlamak son derece önemlidir. Fakat sadece binaların kullanıcı üzerindeki etkilerini anlamak yeterli olmayacağından dolayı kullanıcı sağlığını iyileştiren bir anlayışı benimsemek gereklidir. Bu nedenle yapıların tasarım, inşa ve değerlendirme süreçlerinde yapısal ve mekânsal özelliklerin yanı sıra kullanıcı sağlığının bir kriter olması gerekmektedir. Yeni standartlarda ve yönergelerde sadece olağanüstü durumlarda değil her zaman gerekliliği olan kullanıcıların fiziksel, zihinsel ve sosyal refahını destekleyen kılavuzlara ihtiyaç vardır. Sonuç olarak bina tasarımlarında çevresel kaynakların korunması ve enerji performansını destekleyen sürdürülebilir tasarım kriterlerine ek olarak insanlar için sosyal ve sağlık konularının da yer alması gibi önemli değişikliklerin yapılması beklenmektedir.

\section{Teşekkür ve Bilgi Notu}

$\mathrm{Bu}$ makaledeki bilgi ve belgeler, ulusal ve uluslararası araştırma ve yayın etiğine uygun olarak yazılmıştır. Çalışmada etik kurul izni gerekmemiştir. 


\section{Kaynaklar}

Abidi, S. ve Rajagopalan, P. (2020). Investigating Daylight in the Apartment Buildings in Melbourne, Australia. Infrastructures, 5(10), 81. doi: 10.3390/infrastructures5100081, Erişim Adresi (31.01.2021): https://www.mdpi.com/2412-3811/5/10/81

Altena, E., Baglioni, C., Espie, C. A., Ellis, J., Gavriloff, D., Holzinger, B., ... Riemann, D. (2020). Dealing with sleep problems during home confinement due to the COVID-19 outbreak: Practical recommendations from a task force of the European CBT-I Academy. Journal of Sleep Research, 29(4), e13052. doi: 10.1111/jsr.13052, Erişim Adresi (31.01.2021): https://www.mdpi.com/2412-3811/5/10/81

Amerio, A., Brambilla, A., Morganti, A., Aguglia, A., Bianchi, D., Santi, F., ... Capolongo, S. (2020). Covid19 lockdown: Housing built environment's effects on mental health. International Journal of Environmental Research and Public Health, 17(16), 5973. doi: 10.3390/ijerph17165973, Erişim Adresi (31.01.2021): https://www.mdpi.com/1660-4601/17/16/5973

Ammar, A., Trabelsi, K., Brach, M., Chtourou, H., Boukhris, O., Masmoudi, L., ... Hoekelmann, A. (2020). Effects of home confinement on mental health and lifestyle behaviours during the COVID-19 outbreak: Insight from the "ECLB-COVID19" multi countries survey. MedRxiv. doi: 10.1101/2020.05.04.20091017, Erişim Adresi (31.01.2021): https://www.medrxiv.org/content/10.1101/2020.05.04.20091017v1

Amundadottir, M. L., Rockcastle, S., Khanie, M. S. ve Andersen, M. (2017). A human-centric approach to assess daylight in buildings for non-visual health potential, visual interest and gaze behavior. Building and Environment, 113, 5-21. doi: 10.1016/j.buildenv.2016.09.033, Erişim Adresi

(31.01.2021): https://www.sciencedirect.com/science/article/abs/pii/S0360132316303869

Awada, M., Becerik-Gerber, B., Hoque, S., O'Neill, Z., Pedrielli, G., Wen, J. ve Wu, T. (2020). Ten questions concerning occupant health in buildings during normal operations and extreme events including the COVID-19 pandemic. Building and Environment, 107480 . doi: 10.1016/j.buildenv.2020.107480, Erişim Adresi (31.01.2021): https://www.sciencedirect.com/science/article/pii/S0360132320308477?via\%3Dihub

Baleta, J., Mikulčić, H., Klemeš, J. J., Urbaniec, K. ve Duić, N. (2019). Integration of energy, water and environmental systems for a sustainable development. Journal of Cleaner Production, 215, 14241436. doi: 10.1016/j.jclepro.2019.01.035, Erişim Adresi (31.01.2021): https://www.sciencedirect.com/science/article/abs/pii/S0959652619300411

Committee for the Coordination of Statistical Activities. (2020). How COVID-19 is Changing the World: A Statistical Perspective. Committee for the Coordination of Statistical Activities. (C) Committee for the Coordination of Statistical Activities. Erişim Adresi: https://openknowledge.worldbank.org/handle/10986/33773

Daniela, D. A., Gola, M., Letizia, A., Marco, D., Fara, G. M., Rebecchi, A., ... Capolongo, S. (2020). COVID19 and Living Spaces challenge. Well-being and Public Health recommendations for a healthy, safe, and sustainable housing. doi: 10.23750/abm.v91i9-S.10115, Erişim Adresi (31.01.2021): https://pubmed.ncbi.nlm.nih.gov/32701918/

Dietz, L., Horve, P. F., Coil, D. A., Fretz, M., Eisen, J. A. ve Van Den Wymelenberg, K. (2020). 2019 novel coronavirus (COVID-19) pandemic: built environment considerations to reduce transmission. Msystems, 5(2). doi: 10.1128/mSystems.00245-20, Erişim Adresi (31.01.2021): https://msystems.asm.org/content/5/2/e00245-20

Edwards, L. ve Torcellini, P. (2002). Literature review of the effects of natural light on building occupants. doi: 10.2172/15000841, Erişim Adresi (31.01.2021): https://www.nrel.gov/docs/fy02osti/30769.pdf 
Frank, L. D., Iroz-Elardo, N., MacLeod, K. E. ve Hong, A. (2019). Pathways from built environment to health: a conceptual framework linking behavior and exposure-based impacts. Journal of Transport \& Health, 12, 319-335. doi: 10.1016/j.jth.2018.11.008, Erişim Adresi (31.01.2021): https://www.sciencedirect.com/science/article/abs/pii/S2214140518303360

Hafiz, D. (2015). Daylighting, space, and architecture: a literature review. Enquiry The ARCC .Journal for Architectural Research, 12(1). doi: 10.17831/enq:arcc.v12i1.391, Erişim Adresi (31.01.2021): https://arcc-journal.org/index.php/arccjournal/article/view/391

Hobday, R. A. ve Dancer, S. J. (2013). Roles of sunlight and natural ventilation for controlling infection: historical and current perspectives. Journal of hospital infection, 84(4), 271-282. doi: 10.1016/j.jhin.2013.04.011, Erişim Adresi (31.01.2021): https://www.journalofhospitalinfection.com/article/S0195-6701(13)00154-0/fulltext

Hoisington, A. J., Stearns-Yoder, K. A., Schuldt, S. J., Beemer, C. J., Maestre, J. P., Kinney, K. A., ... Brenner, L. A. (2019). Ten questions concerning the built environment and mental health. Building and Environment, 155, 58-69. doi: 10.1016/j.buildenv.2019.03.036, Erişim Adresi (31.01.2021): https://www.sciencedirect.com/science/article/pii/S0360132319301982

Ilie, P. C., Stefanescu, S. ve Smith, L. (2020). The role of vitamin D in the prevention of coronavirus disease 2019 infection and mortality. Aging Clinical and Experimental Research, 32(7), 11951198. doi: 10.1007/s40520-020-01570-8, Erişim Adresi (31.01.2021): https://link.springer.com/article/10.1007/s40520-020-01570-8

Ingrao, C., Messineo, A., Beltramo, R., Yigitcanlar, T. ve loppolo, G. (2018). How can life cycle thinking support sustainability of buildings? Investigating life cycle assessment applications for energy efficiency and environmental performance. Journal of Cleaner Production, 201, 556-569. doi: 10.1016/j.jclepro.2018.08.080, Erişim Adresi (31.01.2021): https://www.sciencedirect.com/science/article/abs/pii/S0959652618324144

Klepeis, N. E., Nelson, W. C., Ott, W. R., Robinson, J. P., Tsang, A. M., Switzer, P., ... Engelmann, W. H. (2001). The National Human Activity Pattern Survey (NHAPS): a resource for assessing exposure to environmental pollutants. Journal of Exposure Science \& Environmental Epidemiology, 11(3), 231-252, doi: 10.1038/sj.jea.7500165, Erişim Adresi (31.01.2021): https://pubmed.ncbi.nlm.nih.gov/11477521/

Knoop, M., Stefani, O., Bueno, B., Matusiak, B., Hobday, R., Wirz-Justice, A., ... Norton, B. (2020). Daylight: What makes the difference?. Lighting Research \& Technology, 52(3), 423-442. doi: 10.1177/1477153519869758, Erişim Adresi (31.01.2021): https://journals.sagepub.com/doi/10.1177/1477153519869758

Megahed, N. A. ve Ghoneim, E. M. (2020). Antivirus-built environment: Lessons learned from Covid-19 pandemic. Sustainable Cities and Society, 61, 102350. doi: 10.1016/j.scs.2020.102350, Erişim Adresi https://www.sciencedirect.com/science/article/abs/pii/\$2210670720305710

(31.01.2021):

Moccia, L., Janiri, D., Pepe, M., Dattoli, L., Molinaro, M., De Martin, V., ... Di Nicola, M. (2020). Affective temperament, attachment style, and the psychological impact of the COVID-19 outbreak: an early report on the Italian general population. Brain, Behavior, and Immunity, 87, 75-79. doi: 10.1016/j.bbi.2020.04.048, Erişim Adresi (31.01.2021): https://www.sciencedirect.com/science/article/abs/pii/S0889159120305869

Morin, C. M., Carrier, J., Bastien, C. ve Godbout, R. (2020). Sleep and circadian rhythm in response to the COVID-19 pandemic. Canadian Journal of Public Health, 111(5), 654-657. doi: 10.17269/s41997-020-00382-7, Erişim Adresi (31.01.2021): https://link.springer.com/article/10.17269\%2Fs41997-020-00382-7

Mujan, I., Anđelković, A. S., Munćan, V., Kljajić, M. ve Ružić, D. (2019). Influence of indoor environmental quality on human health and productivity-A review. Journal of Cleaner 
Production, 217, 646-657. doi: 10.1016/j.jclepro.2019.01.307, Erişim Adresi (31.01.2021): https://www.sciencedirect.com/science/article/abs/pii/S0959652619303348

Odriozola-González, P., Planchuelo-Gómez, Á., Irurtia, M. J. ve De Luis-García, R. (2020). Psychological effects of the COVID-19 outbreak and lockdown among students and workers of a Spanish university. Psychiatry Research, 290, 113108. doi: 10.1016/j.psychres.2020.113108, Erişim Adresi

(31.01.2021):

https://www.sciencedirect.com/science/article/abs/pii/S0165178120313147

Pfefferbaum, B. ve North, C. S. (2020). Mental health and the Covid-19 pandemic. New England Journal of Medicine, 383(6), 510-512. doi: 10.1056/NEJMp2008017, Erişim Adresi (31.01.2021): https://www.nejm.org/doi/full/10.1056/NEJMp2008017

Pinheiro, M. D. ve Luís, N. C. (2020). COVID-19 could leverage a sustainable built environment. Sustainability, 12(14), 5863. doi: 10.3390/su12145863, Erişim Adresi (31.01.2021): https://www.mdpi.com/2071-1050/12/14/5863

Rhodes, J. M., Subramanian, S., Laird, E., Griffin, G. ve Kenny, R. A. (2021). Perspective: Vitamin D deficiency and COVID-19 severity-plausibly linked by latitude, ethnicity, impacts on cytokines, ACE2 and thrombosis. Journal of internal Medicine, 289(1), 97-115. doi: 10.1111/joim.13149, Erişim Adresi

(31.01.2021): https://www.researchgate.net/publication/342641240_Perspective_Vitamin_D_deficiency_an d_COVID-19_severity__plausibly_linked_by_latitude_ethnicity_impacts_on_cytokines_ACE2_and_thrombosis_R1

Saadat, S., Rawtani, D. ve Hussain, C. M. (2020). Environmental perspective of COVID-19. Science of the Total Environment, 138870. doi: 10.1016/j.scitotenv.2020.138870, Erişim Adresi (31.01.2021): https://pubmed.ncbi.nlm.nih.gov/32335408/

Schuit, M., Gardner, S., Wood, S., Bower, K., Williams, G., Freeburger, D. ve Dabisch, P. (2020). The influence of simulated sunlight on the inactivation of influenza virus in aerosols. The Journal of infectious Diseases, 221(3), 372-378. doi: 10.1093/infdis/jiz582, Erişim Adresi (31.01.2021): https://pubmed.ncbi.nlm.nih.gov/31778532/

Thompson, C. W. (2013). Activity, exercise and the planning and design of outdoor spaces. Journal of Environmental Psychology, 34, 79-96. doi: 10.1016/j.jenvp.2013.01.003, Erişim Adresi (31.01.2021): https://www.sciencedirect.com/science/article/abs/pii/s0272494413000054

Tokazhanov, G., Tleuken, A., Guney, M., Turkyilmaz, A. ve Karaca, F. (2020). How is COVID-19 experience transforming sustainability requirements of residential buildings? A review. Sustainability, 12(20), 8732. doi: 10.3390/su12208732, Erişim Adresi (31.01.2021): $10.3390 /$ su12208732

Ullah, I. (2014). Daylight for healthy indoor environment and energy benefits. Int. J. of Ophthalmology \& Eye Sci, 2(2), 1-2, doi: 10.19070/2332-290X-140003e, Erişim Adresi (31.01.2021): https://scidoc.org/IJOES-2332-290X-02-002e.php

Wang, C., Pan, R., Wan, X., Tan, Y., Xu, L., Ho, C. S. ve Ho, R. C. (2020). Immediate psychological responses and associated factors during the initial stage of the 2019 coronavirus disease (COVID19) epidemic among the general population in China. International Journal Of Environmental Research and Public Health, 17(5), 1729. doi: 10.3390/ijerph17051729, Erişim Adresi (31.01.2021): https://www.mdpi.com/1660-4601/17/5/1729

World Health Organization. (1948). Preamble to the Constitution of WHO as Adopted by the International Health Conference, New York, 19 June - 22 July 1946; Signed on 22 July 1946 by the Representatives of 61 States (Official Records of WHO, No. 2, p. 100) and Entered into Force on 7 April 1948. Erişim Adresi (31.01.2021): https://apps.who.int/gb/bd/

World Health Organization. (2013). Combined or multiple exposure to health stressors in indoor built environments. Erişim Adresi (31.01.2021): https://www.euro.who.int/en/health- 
topics/environment-and-health/air-quality/publications/2014/combined-or-multipleexposure-to-health-stressors-in-indoor-built-environments

World Health Organization. (2020). WHO director-General's opening remarks at tha media briefing on COVID19 - 11 march 2020. Erişim Adresi (31.01.2021): https://www.who.int/directorgeneral/speeches/detail/who-director-general-s-opening-remarks-at-the-media-briefing-oncovid-19---11-march-2020 